\title{
IT Governance: Oil or Sand in the Wheels of Innovation?
}

\author{
Maral E. Arikan \\ ABN AMRO \\ maral.arikan@nl.abnamro.com
}

\author{
Hans P. Borgman \\ University of Amsterdam Business School \\ h.p.borgman@uva.nl
}

\begin{abstract}
The purpose of this study is to understand how IT Governance (ITG) can foster or hinder the development and roll-out of radical or disruptive IT-enabled innovations. Propositions derived from the extant literature guide the analysis of seven embedded case studies of different innovation initiatives within a single large Dutch multinational bank with various contingency factors affecting ITG across the cases. Our findings confirm and extend earlier studies that emphasize the importance of proper business-IT communication and identify challenges caused by long gatekeeping processes and by the use of novel technologies in a traditional IT landscape. Radical or disruptive innovations also add new challenges, as they often cross business lines and therefore may be exposed to a heterogeneous set of ITG mechanisms. Our study further demonstrates that these innovations demand a different approach on an IT-functional level and a reconsideration of the risk capability structure to optimize efficiency.
\end{abstract}

\section{Introduction}

Digital transformation is causing a radical shift in business practices, business models and industry boundaries, impacting almost all sectors of the economy [1]. Organizations seek effective use of new technologies to defend or strengthen their competitive position. Consequently, organizations become more dependent on their IT resources [2], [3], and studies show that firms with a strong digital leadership report a higher profitability $(+23 \%)$ as well as a higher market valuation $(+12 \%)$ compared to firms that lack this [4]. To keep up with the changing business environment, the pace of IT systems delivery is crucial, which requires a new form of governance and structures to ensure effective strategy execution [3]. Although the required entrepreneurial alertness [5] is typically in place, organizations experience high barriers on their way to digital transformation such as complex business processes, high capital costs and regulatory roadblocks [6]. The IT function supports the business in this transformation [7] and ITG places structure around the way the IT strategy delivers business value, pushing the importance of ITG on the corporate agenda [8]. ITG is defined here as the definition and implementation of processes, structures, and relational mechanisms in the organization concerning the oversight of IT assets, their contribution to business value and the mitigation of ITrelated risk [8]-[10].

When looking at innovations, different types can be distinguished, including sustaining, disruptive, and radical innovations [11] [12]. Considering the scope of our research, our focus is on IT-enabled disruptive and radical innovations, innovations that have the potential to either disrupt the market by offering new value propositions, or to radically change a subsystem of the organization by the usage of new technology.

Established organizations typically face a large amount of legacy within their infrastructure in the form of systems, applications and data [9]. Mastering this 'old world' while embarking on IT-enabled innovation projects, particularly when they are radical or disruptive, is a challenge many firms struggle with, illustrated by the high rate of discontinued or failed innovation projects [13]. To improve this, ITG frameworks such as COBIT (Control Objectives for Information and related Technology) and IT service management frameworks such as ITIL offer guidance [9]. However, the complex dynamics of IT governance and IT-enabled innovation, combined with rapid changing technologies and high levels of uncertainty and change, continue to pose new challenges to ITG processes, structures and mechanisms [14]. The purpose of our research, therefore, is to improve our understanding of how ITG can foster or hinder the development and roll-out of radical or disruptive IT-enabled innovations.

To guide our research and data-collection we develop -in section 2- five propositions based on the extant literature. A more detailed discussion of the research method follows in section 3 , after which we briefly describe the cases (4) and then use the propositions to present our cross-case analysis (5), followed by a discussion (6), including suggestions for future research. 


\section{Literature review}

The aforementioned critical dependency on IT calls for effective IT governance, across the organization as well as at board level [15]. Organizations with wellgoverned IT, through an improved IT capability, demonstrate a higher firm performance [10], [16]. Mounting regulatory pressures, related to areas such as confidentiality, financial accountability and data retention further add to the importance of ITG [15], [17]. The 'process' aspect of ITG concerns both portfolio as well as project level [18]. At both levels, radical or disruptive IT-enabled innovations add specific ITG process challenges. These innovation projects often start as a small experiment without a concrete pre-specified end product [11] indicating their highly exploratory character. Agile working practices further add to the complexities of managing IT innovations at both project as well as portfolio level, requiring a challenging combination of flexibility and clarity in governance processes to ensure progress [19]. This brings us to the first proposition.

P1: Unclear governance processes cause inertia when organizations are trying to develop and deploy innovative projects.

IT infrastructure management consists of the decisions that establish hardware and software platforms by planning, building and deployment of network and data architecture, and deliver capabilities and corporate standards for procurement and development of IT assets [20]. Established firms are relentlessly investing in IT capabilities, such as cloud computing, microservices and data lakes, in order to innovate and create business value [21]. In that process, they face legacy within their infrastructure which should be managed to co-exist with the modern technologies, causing technical as well as organizational complexities [9]. These complexities, including issues around data definitions and incompatible (operating) systems, often hamper innovation speed [22]-[24]. This provides a foundation for our second proposition:

P2: IT infrastructure challenges are limiting organizations in enabling a fast time-to-market for innovative projects.

Time-to-market is a key driver in innovation and speed is the main driver for successful product innovation. The faster a firm goes from development to deployment [25], and the faster they are able to scale [6], the more likely they are to generate profits and gain market share [6], [25]. Next to speed of delivery, IT infrastructure flexibility is an important factor for innovation within organizations [26]-[28], as it leads to an infrastructure that is better scalable and adaptable, making organizations more responsive and faster. Reacting to fast changing markets involves a combination of tight alignment and flexible IT infrastructures. IT infrastructure flexibility has a significant impact on agility, and agility positively impacts firm performance. Simultaneously, agility is more difficult to attain for firms that are more traditional (larger, older or operating in more traditional industries) [28], bringing us to our third proposition:

P3: Both business and IT processes are less flexible where new technology is used in established firms.

IT architecture and IT infrastructure are sometimes used interchangeably [29]. We refer to IT architecture as an organization's list of technology standards, principles and policies, where the complex linkages between processes, infrastructure, data and applications are defined to enable an organization's strategic objective [29], [30] and mitigate risks [13].

A recent market study by a leading software integration provider showed that $89 \%$ of IT decisionmakers face challenges when integrating the physical and digital environments, hindering digital transformation. Point-to-point integration is viewed by $81 \%$ as one of their greatest concerns (MuleSoft 2018) making operational alignment, flexibility and transparency of the architecture characteristics valued as most important [18]. In most organizations, the architecture decisions are taken by IT and the investment decisions by the business domains [30]. In large organizations, the IT functions are often scattered across different domains in the organization -in a hybrid or federated form - which complicates effective IT architecture management [31].

Governance mechanisms guard architecture management and enforce desirable behavior using organizational structures, committees, boards and policies, among others [30]. This can improve re-use and synergize initiatives reducing complexity and increase agility over time [9]. This has also been theorized by Weill and Ross [32] who claim that proper organizational structure and IT governance design allow for simultaneously achieving effectiveness (IT business value) and efficiency (return on assets) [32]. In line with our discussion in the previous sections, IT infrastructure flexibility has a positive and significant effect on agility [26], where the transformation to organizational agility leads to more focus on business value and less on IT project control [19]. When looking at innovation, a stronger reliance on IT governance mechanisms - in the form of boards and committees - leads to less process or product innovation [33]. However risk plays a major role in innovation projects [13], resulting in 
organizations integrating risk officers in their governance structures [34]. This impacts organizations by locking out creativity, which is crucial to innovation, caused by excessive risk management in organizations [13], [22]. The above leads to our fourth proposition:

\section{P4: Committees, boards and policies have a greater risk avoidance for projects where new technology is used, causing inertia.}

Risk is strongly connected to uncertainty, and firms today are faced with a high level of uncertainty [24] that can be associated with different forces, within as well as outside the firm boundaries [20]. To deal with this uncertainty, organizations require a high level of agility [24], putting additional strain on an already difficult task:. business-IT alignment [26]. Where IT managers have the necessary know-how regarding technology, ITenabled innovations are led by business owners who can grasp the business situation [1]. Misalignment between the business and IT can form a barrier when the desires are formed in isolation without general alignment [24] and enterprises cannot be competitive with a misalignment between the business and IT strategies [35]. In early studies this has been argued by Henderson and Venkatraman [36], who argue for a fit between the vision of the organization within the market in which it operates, and the design of an appropriate structure to guide the execution [36]. Exploiting opportunities arising from digitization make this alignment even more pressing as innovation is often driven by IT [33] and information systems success and competitive advantage demand effective alignment [18]. Organizations who tend to approach the business-IT alignment less flexible may stifle themselves, effectively blocking innovation [33]. Strategic advantage in the digital economy should be reached through hybrid processes [28]. This then brings us to the last proposition.

P5: Complexity and uncertainties in innovation portfolio management demand stronger Business-IT alignment than traditional portfolio management to become successful.

\section{Research method}

A case study research design was chosen, due to the complex and contextual nature of IT governance and the lack of generally accepted theories in this area [37]. Cases were selected based on relevance and uniqueness, whereafter they were tested for fit to the study, meaning cases that could be classified as either radical or disruptive innovations, and cases that were 'complete', meaning they had reached an end stage in the form of discontinuation or going live. Next to desk research (primarily using detailed internal company documents),
2 to 4 semi-structured interviews were conducted for each case. Prior to the interviews, an interview guideline was designed, based on the propositions, to ensure focus and completeness/uniformity across the interviews. Data source triangulation [38] was used to cross-check data across interview and document data, which contributes to the validity of our research findings. The interviewees were selected on the basis of seniority and function; they include both IT and business owners, all with a large amount of experience. The interviews ranged between 45 and 60 minutes each and were recorded and transcribed. The transcribed interviews were subsequently coded and analyzed using NVivo, using codes derived from the propositions as starting points, supplemented with additional codes as these emerged during the coding process. Axial and selective coding in subsequent coding rounds completed this process. The interview guideline was identical for both business and IT executives, with minor adjustments depending on the perspective of the interviewee.

\section{Cases}

For the case selection we selected seven cases, all within a single large multinational financial services company (embedded cases); elements such as IT governance processes and structures are therefore identical across the cases, which allows us to focus on the role of relational mechanisms that play out differently for each case, whereafter we are able to explore how radical or disruptive innovations are impacted by these mechanisms. For a discussion of IT governance processes, structures, and relational mechanisms see [39]. Table 1 presents the (anonymized) case names, the role of the interviewees and their experience level.

\section{Table 1. Case and interviewee overview}

\begin{tabular}{|l|l|l|}
\hline \multicolumn{1}{|c|}{ Case ID } & \multicolumn{1}{|c|}{ Interviewee } & \multicolumn{1}{c|}{ Experience } \\
\hline Block Estate & 1 Data Scientist & $3-5$ years \\
& 1 Product Owner & 3 years \\
& 1 Solution Engineer & $>10$ years \\
& 1 IT-integrator & $>10$ years \\
\hline B2C app & 1 Data Enterprise advisor & $>10$ years \\
& 1 Product Owner & $>5$ years \\
& 1 Business Owner & $>10$ years \\
\hline Spendfix app & 1 Project Manager & $>10$ years \\
& 1 Solution Engineer & $>15$ years \\
& 1 Engineering lead & $>15$ years \\
\hline Peer2Peer Pay & 1 Scrum Master & $>5$ years \\
& 2 Solution Engineers & $>15$ years (both) \\
& & \\
\hline Risk Rater & 1 Innovation Manager & $>5$ years \\
& 1 Solution Engineer & $>15$ years \\
& 1 Business Owner & $>10$ years \\
\hline Moonshot & 1 Innovation Manager & $>5$ years \\
& 1 Solution Engineer & $>15$ years \\
& 1 Developer & $>10$ years \\
\hline RPA & 1 Operations Specialist & $>5$ years \\
& 2 Product Owners & $>10$ years (both) \\
& 1 Developer & $>10$ years \\
\hline
\end{tabular}



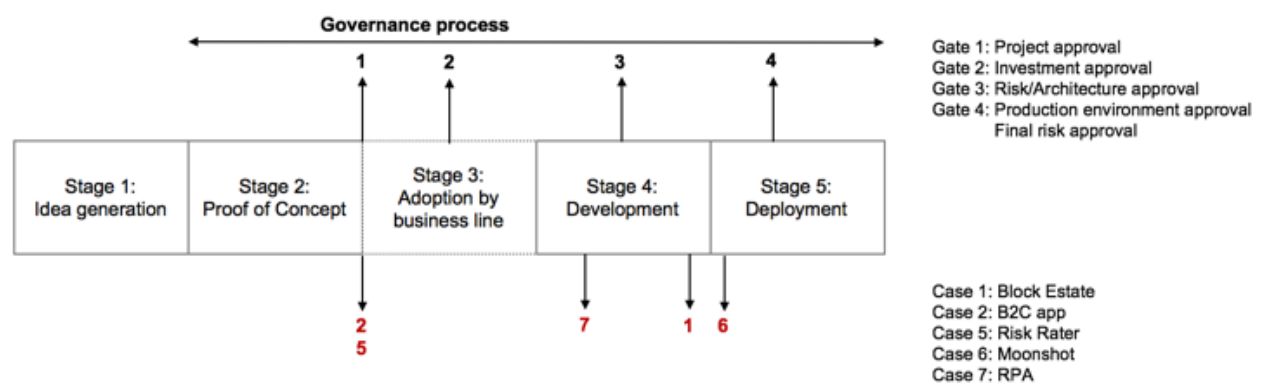

Fig. 1: Stage-gate project flow

Case 6: Moonshot

All cases were managed as projects or initiatives that followed a stage-gate process, shown in figure 1 (Fig 1). The gates that govern the project are listed at the top of the figure, gate 2 and stage 3 only apply to projects that start outside of the business line. The discontinued cases $(2,5,7,1$ and 6) are mapped at their 'exit' point at the bottom of the process flow in red. The 2 cases that did reach the going-live moment after stage 5 (case 3 and 4) are therefore not listed in fig. 1. As mentioned, all cases or initiatives were studied in the same large organization, thereby controlling for IT governance structures and processes.

Table 2 provides brief descriptions of each case, our assessment of the nature of the innovation inherent to the project (disruptive or radical), the observed reliance on each of the four main IT governance mechanisms [39], as well as the duration of the project. The reliance on each governance mechanism is designated by ++ for a strong reliance, + for a moderate role and - when the mechanism did not play any noticeable role. IT governance roles and responsibilities, for this organization, are guided by COBIT.

\section{Cross case analysis}

The cross case analysis follows the propositions, while still allowing for additional insights in line with the explorative nature of the study [40]. Figure 2 offers an overview of the challenges encountered for each case, with challenges (listed at the right) ranging from IT/Business alignment to Architecture control. The width of each connecting line indicates our assessment of the relative magnitude of each challenge, based on our analysis of the collected data.

\subsection{P1: Governance processes}

In general the data show strong support for the first proposition which suggests that inertia is caused by unclear governance processes when trying to develop and deploy innovative projects. Five of the seven cases experienced challenges regarding unclear processes and no clear direction upfront regarding governance mechanisms the projects had to adhere to. The interviewees experienced little flexibility with IT portfolio management. The data confirm the theory that the organizational mindset is there [5], but there are barriers in going to the deployment phase [22], [27]. "It is not so much the mindset, but mainly the procedures and policies that prohibit us to accelerate" (Solution Engineer, Risk Rater).

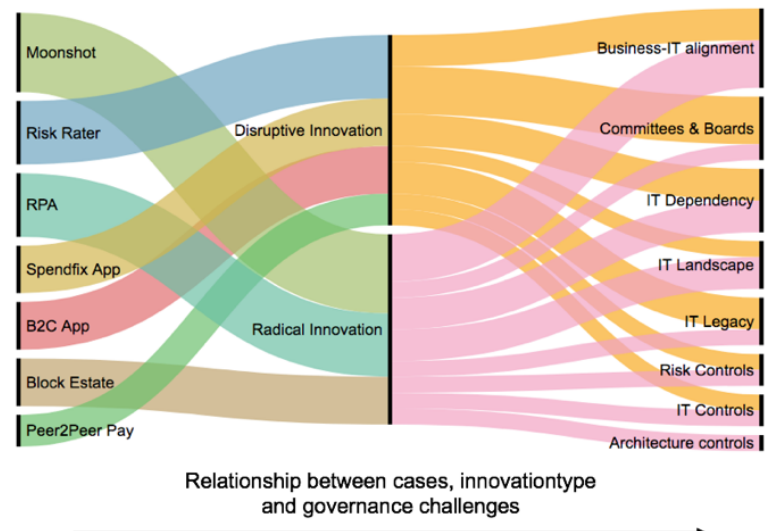

Fig. 2: IT Governance challenges per case

Furthermore, we observed that projects with team members in the lead that had little experience within the organization faced more difficulties going through the governance process versus those who had substantial more years of experience. Both cases Peer2Peer pay and Spendfix benefited from experienced and knowledgeable team members with regards to the IT landscape and governance processes. "There were a lot of new colleagues that worked a lot on innovation, but were not used to all the checks. The Product Owner and I guided the whole process [...] I know the ins and outs of the organization, I knew most developers and the Product Owner clearly stated that I was in the lead, so there were no discussions on that end" (Solution Engineer, Spendfix).

Especially the initiatives that started outside business lines experienced difficulties making an estimation on the utilization mechanisms regarding the 
governance process. "I did not have a clear view of the process, but we soon saw the first hurdles of going to production. Thinking, can't we go to an environment where we have more mandate to arrange our own business." (Solution Engineer, Moonshot). Especially in innovation projects we observed high uncertainty concerning technology and security governance. This resulted in excessive work to provide clarifications.
"We literally got a list with 150 items which we had to adhere to, and how? We had to figure it out ourselves. I get the concern, but you can also lend a hand when working on innovation" (Innovation Manager, Moonshot). Imposing transparent and cooperative governance processes can offer an accelerator for innovation projects.

Table 2. Case study overview: innovation type and governance mechanisms

\begin{tabular}{|c|c|c|c|c|c|c|c|}
\hline \multirow[t]{2}{*}{ CaseID } & \multirow[t]{2}{*}{ Description } & \multirow{2}{*}{$\begin{array}{l}\text { Innovation } \\
\text { type }\end{array}$} & \multicolumn{4}{|c|}{ IT Governance Mechanisms } & \multirow{2}{*}{$\begin{array}{l}\text { Duration of } \\
\text { the project in } \\
\text { months }\end{array}$} \\
\hline & & & $\begin{array}{l}\text { IT/ } \\
\text { Business } \\
\text { partnersh } \\
\text { ips }\end{array}$ & $\begin{array}{l}\text { Stakehol } \\
\text { der } \\
\text { participat } \\
\text { ion }\end{array}$ & $\begin{array}{l}\text { Shared } \\
\text { Learning }\end{array}$ & $\begin{array}{l}\text { Roles \& } \\
\text { responsib } \\
\text { ilities }\end{array}$ & \\
\hline $\begin{array}{l}\text { 1: } \\
\text { Block Estate }\end{array}$ & $\begin{array}{l}\text { Real estate project, where blockchain was introduced to } \\
\text { resolve excessive documentation and data quality issues. The } \\
\text { project was split into } 2 \text { pillars. One pillar was working on the } \\
\text { front-end, involving the parties that are involved in the real } \\
\text { estate process outside the organization, the } 2^{\text {nd }} \text { pillar was the } \\
\text { back-end of the project. Building the application that had to } \\
\text { be connected to the blockchain and connecting the app to the } \\
\text { IT landscape. }\end{array}$ & $\begin{array}{l}\text { Radical } \\
\text { Innovation }\end{array}$ & - & + & + & - & $\begin{array}{l}\text { Discontinued } \\
\text { after } 12 \\
\text { months }\end{array}$ \\
\hline $\begin{array}{l}\text { 2: } \\
\text { B2C app }\end{array}$ & $\begin{array}{l}\text { Project focused on simplifying the contact between } \\
\text { accountmanager and client. Account managers are forced to } \\
\text { use a laptop to get insights in leads for clients that need follow } \\
\text { up. The project developed a mobile app which was fed with } \\
\text { algorithms to provide additional and valuable leads. }\end{array}$ & $\begin{array}{l}\text { Disruptive } \\
\text { Innovation }\end{array}$ & - & - & + & - & $\begin{array}{l}\text { Discontinued } \\
\text { after } 18 \\
\text { months }\end{array}$ \\
\hline $\begin{array}{l}\text { 3: } \\
\text { Spendfix } \\
\text { App }\end{array}$ & $\begin{array}{l}\text { Project that gives clients insight in their spending by } \\
\text { providing an app that categorizes and classifies transaction } \\
\text { data through AI and was offered as a new business } \\
\text { proposition. }\end{array}$ & $\begin{array}{l}\text { Disruptive } \\
\text { Innovation }\end{array}$ & + & + & + & + & $\begin{array}{l}\text { Live after } 4 \\
\text { months }\end{array}$ \\
\hline $\begin{array}{l}\text { 4: } \\
\text { Peer2Peer } \\
\text { Pay }\end{array}$ & $\begin{array}{l}\text { Initiative of mobile banking for peer-to-peer payments via a } \\
\text { mobile phone without entering an up to } 43 \text {-digit number, but } \\
\text { sending payment requests through a link. }\end{array}$ & $\begin{array}{l}\text { Disruptive } \\
\text { Innovation }\end{array}$ & + & + & + & + & $\begin{array}{l}\text { Live after } 9 \\
\text { months }\end{array}$ \\
\hline $\begin{array}{l}\text { 5: } \\
\text { Risk Rater }\end{array}$ & $\begin{array}{l}\text { Project that offers Risk as a Service. Using smart models } \\
\text { making analysis and risk assessments for clients. This risk } \\
\text { rating shows whether a client is creditworthy without } \\
\text { excessive documentation. }\end{array}$ & $\begin{array}{l}\text { Disruptive } \\
\text { Innovation }\end{array}$ & + & + & - & - & $\begin{array}{l}\text { Discontinued } \\
\text { after } 19 \\
\text { months }\end{array}$ \\
\hline $\begin{array}{l}\text { 6: } \\
\text { Moonshot }\end{array}$ & $\begin{array}{l}\text { Moonshot project that would go beyond the traditional } \\
\text { business model. The project challenged the question 'Can we } \\
\text { design and build a platform that can run any financial service } \\
\text { on any scale at extreme low costs?'. After a validation of the } \\
\text { blueprint, the project started with an MVP within the small } \\
\text { and medium enterprise department, using new technology to } \\
\text { create loans and also foresee in the monitoring. }\end{array}$ & $\begin{array}{l}\text { Radical } \\
\text { Innovation }\end{array}$ & - & + & - & - & $\begin{array}{l}\text { Discontinued } \\
\text { after } 12 \\
\text { months }\end{array}$ \\
\hline $\begin{array}{l}7: \\
\text { RPA }\end{array}$ & $\begin{array}{l}\text { Robotic process automation project within the investments } \\
\text { department to digitize manual processes using the latest } \\
\text { Robotic Technology. }\end{array}$ & $\begin{array}{l}\text { Radical } \\
\text { Innovation }\end{array}$ & - & + & + & - & $\begin{array}{l}\text { Discontinued } \\
\text { after } 18 \\
\text { months }\end{array}$ \\
\hline
\end{tabular}

\subsection{P2: IT Infrastructure}

Across the seven cases we found a strong correlation between the current infrastructural landscape, at time of execution, and the time to market for innovative projects, giving strong support for the $2^{\text {nd }}$ proposition: the current infrastructural landscape is limiting organizations in enabling a fast time-tomarket for innovative projects. Undeniably, the fast pace and quick rise of new technologies offers opportunities for firms. Cloud computing is one of the emerging technologies leading to the next generation of internet by providing efficient computing through enhanced collaboration, agility, scalability and availability [41]. However, making use of these new technologies within traditional organizations does not come without challenges. Often projects need a connection to the old world for data retrieval, or to connect to other applications. The Peer2Peer pay demonstrates the challenges of this 'old world' when processing the big batches of data. "The back-end service was still on premise. With every payment, a batch of 1000 runs through, it could not handle the load. You see growing pains with new technology that is linked to back-end services" (Solution Engineer, 
Peer2Peer pay). The new applications are stored in the cloud but run with data of on-premise systems highlighting another challenge. The databases are often scattered all over the IT-landscape, designing a solution architecture is often complex. "We had to setup data-pipelines. We use one CRM system but the data in that system comes from different golden sources [...] you end up with a difficult structure of all sorts of databases.. this resulted in quite some discussion." (Data Enterprise Advisor, B2C app). The solution engineer of Moonshot project stated the same, "The AI needs data.. you heard everyone complain. We can't make models without the data, $80 \%$ of the time we got stuck in finding the right data and extracting it from the legacy systems" (Solution Engineer, Moonshot).

This brings us to another infrastructural challenge: Organizations mainframe computers often host the most critical applications. This system architecture holds old technology and few teams specialize in these systems "The development cycle for the mainframe is very long, just a few people can make adjustments." (Solution Engineer, Risk Rater). Additionally, the scattered IT landscape of the on-premise server adds complexity, proved by the Product Owner of the B2C app stating, "To give the full client view you already deal with 70 interfaces... there are around 10.000 processes a banker can start, everything has its own system [...] there are just a few people who have the full overview". Dependencies on current IT infrastructure are viewed as limiting by five of the seven projects. This challenge is also visualized in the cross-case map in figure 2 , where the degree of dependency on IT infrastructure is the main driver of this challenge. To illustrate: "Projects that are more dependent of legacy systems have a harder time innovating. They first have to build services and do some refactoring via microservices before they can proceed" (Solution Engineer, Spendfix).

An engineer referred to manual plumbing, explaining the manual tasks that need to be taken in order to find, clean and use data. Nevertheless, you do see that with new techniques there are also ways to go around legacy systems by the usage of ESB's, API gate-way's and services. "The mainframe is a challenge, but it limits us less and less." (Engineer Lead, Spendfix). Indicating that it may be a matter of time before these hurdles belong to the past.

\subsection{P3: IT-process controls}

Our data shows no clear support for the $3^{\text {rd }}$ proposition: Both business and IT processes are less flexible where new technology is used in established firms. Although there is no direct support for the third proposition, the data does show how cases experienced struggles with the perceived rigid processes. IT infrastructure flexibility can be an important component in the ability for an organization to react on market opportunities [26]. Our data shows that development and deployment was rather organization specific, delaying time to market and being reactive to these market opportunities. "Within the organization we use certain widgets, we could not use the webpage we made for the PoC, instead our external developer had to follow a training to learn how to build it in that organization specific widget..." (Solution Engineer, Risk Rater). Our observations show that teams are encouraged to work autonomously and become self-organizing, but simultaneously organizations standards, guidelines and the development environment are restrictive and hamper quick development and deployment, which is vital for innovative projects. Several interviewees stress the desire for a more standardized approach when it comes to system architecture solutions and a reserved governance model eliminating the excessive restrictions, also theorized by Ross [29]. This approach is underlined by the following quote; "We give projects a set of rules which we guard at architecture level. We don't offer a lot of standardized, off-the-shelf solutions which are securely installed and ready" (Solution Engineer, Moonshot)

Both Peer2Peer pay and Spendfix, the only projects that went live, started with external hosting for their application, as the cloud was not part of the organizational infrastructure yet. "We had to build using predefined infra. The cloud wasn't an option, as we could not use SQL. We decided to host it external" (Solution Engineer, Spendfix). The demand to deploy on the Cloud within the organization took flight several months later and the IT parties introduced two public Cloud platforms. Due to the novelty of these platforms new challenges occurred in stage 4 (fig. 1) as specific Cloud governance mechanisms were not in place apparent in the following quote; "IT-services plotted their old business model on the new organization [...] Everyone wants to go to public cloud and they bring all the same gates there" (Engineering lead, Spendfix). The absence of Cloud governance mechanisms impacted the cases Moonshot and Block Estate that recruited external developers for the project. "The developers were AWS developers, but within our organization we have put all these restrictions on the AWS cloud. [...] They were continuously going back to IT with questions, can you open this portal, or make that available. [...] It was a big trial and error" (Innovation Manager, Moonshot). This example stresses the importance of specialized IT-teams offering support towards end-users 
embracing cloud solutions theorized by [41] as well as a need for a supportive IT function to effectively support digitization for the long term [7], focused on increasing the business value [19]. Moreover, we observed that roles and responsibilities are scattered throughout the organization, as well as outsourced to external strategic partners. Several interviewees stress their concerns with these decentralized owners and its impact on on-time delivery, apparent in the following statement; "With innovation you sometimes run into a designing problem, that is not an incident, but you have to act fast, if we have to wait several weeks or months to have it implemented, this is unacceptable... Most successful companies do several deployments a day" (Solution Engineer, Risk Rater). Spendfix, Moonshot, Block Estate, RPA and the B2C app viewed these development cycles as barriers. "We faced old school releases. We had to announce the change 8 weeks upfront" (Solution Engineer, Spendfix). This was also illustrated in another case; "For testing and scaling we were dependent of our IT partner. We had different running speeds, getting the test environment, loading data, it took forever. You quickly become the weakest link" (Product Owner, RPA). Finally, IT process controls are unchanged, underlined in the following statement, "The process was set-up like regular IT-projects [...] you go through all the same processes" (Solution Engineer, Moonshot). The interviewees emphasize that reconsideration of the governance processes is desirable, especially when it comes novel technologies.

\subsection{P4: Risk avoidance}

Our findings show that risk avoidance seems more excessive with innovative projects. Four out of seven cases accounted for strong support of the $3^{\text {rd }}$ proposition; Committees, boards and policies have greater risk avoidance for projects where new technology is used, causing inertia.

Observations show that the cases using radical innovation (Moonshot, Block Estate and Reframe) faced the most difficulties with checks, assessments and boards within stage 4 and 5 of the process (fig. 1). This can be explained by the explorative and highly experimental character of these radical or disruptive innovation projects. Additionally, a number of interviewees expressed their frustration with the governance process around the public Cloud platforms. Although the Cloud was intended as an enabler for innovative solutions, our data shows that, next to the traditional governance, additional gatekeepers were implemented. "With the license to public for cloud, the organization set-up 7 new gates to check whether you have a valid business case, check if the knowledge is in place, whether the team functions as an autonomous devops team etc. Everywhere they put new gates, this slows down our development." (Engineering Lead, Spendfix). Similarly, the IT-integrator of Block Estate described "The license to public process took me 2 months, the stage of going to the cloud approval board in order to reach deployment stage then still had to come".

The governance in the Cloud is done by a separate committee. This is where several cases raised their concerns in terms of accelerating their strategic value propositions. Within stage 4 , the development stage, developers are entitled to a test environment, referred to as the 'sandbox'. Interviewees describe the sandbox as an environment without many limitations. However, when the project is ready to go to deployment, the governance rules become effective. This is described as a "One-size-fits all" approach. Highlighted in the following statement, "Exploring is quite easy, as long as no client data is involved they'll provide you an environment. However, if you want to do anything on production, even a test with 50 clients, all the heavy gates apply" (Solution Engineer, Moonshot). Different risk parties are responsible for a part of the risk capability. These novel technologies ask for a different level of technical maturity, resulting in excessive elaboration and discussion as described by Peer2Peer pay, Spendfix, Moonshot and RPA. Amplifying uncertainty avoidance of the risk parties extending project timelines.

Exploring is a great part of innovation and creativity suffers from heavy risk management [33] the Solution Engineer of Moonshot stated; "There are a lot of gates on innovation, there is no governance design on innovation where they say, this is an innovative project we have applied some general risk mitigating measurements so you can act within that framework". These statements are underlined by the Innovation Manager of Risk Rater who advocates for an intermediate governance model, a mode which lies between, on paper, and real-time development. Granular going to the right solution instead of going live with a big bang.

\subsection{P5: Business-IT alignment}

Within the case study we found a clear relation between complexity, uncertainties and the need for stronger business-IT alignment. Offering strong support for the $5^{\text {th }}$ proposition: Complexity and uncertainties in innovation projects demand stronger Business-IT alignment to become successful. Also shown in figure 2 where the governance mechanism business-IT alignment shows its impact on most cases. 
Two projects were discontinued after the proof of concept phase (fig. 1) lacking a dedicated sponsor within the business line. Our observations show that innovative projects, often exceed business lines. The only cases that went live, were initiated in a specific business line. The organizational structure lacks support for overarching projects, theorized as siloinnovation where all initiatives only serves local value propositions [22]. This theory is supported by our data; "I noticed the mentality, a new project.. people are looking for a known path, how to approach it. This was a whole new project, not in one business line, it [involved] people of multiple business lines" (Product Owner, B2C app). A similar statement was made by the Solution Engineer of Moonshot; "It is all great as long as it is exploratory, everyone is enthusiastic, but the moment you say, let's [make it real], you get stuck in the existing organizational structure with own agenda's and goals. How do you bridge that..".

Many projects faced difficulties going from stage 2 to 3 (fig. 1) also characterized as the 'Eternal Proofof-Concept'. Moreover, we found that the B2C app, Moonshot, Block Estate and Risk Rater all started with great ambition, but when it comes to tangible solutions, it is perceived as problematic to bring creativity together with the current system architecture. From big, visionary, future proof and tech savvy, the projects slowly transform to incremental improvements of the old world. It is a deflating balloon effect where, with every additional stakeholder participation and requirement, a bit of air from the balloon is released.

Finally, the projects indicated that they deal with a lot of stakeholders who all have to be managed. The Innovation Manager of Moonshot stated; "There is quite some distance between the AWS team and our team, distance between our team and the security team. These are all new silos [...] delaying our time to market". Both cases that did make it to production invested a lot in stakeholder management "You noticed that a relationship is very important, we had to do a lot with security and encryption, so involving the security and compliance parties in an early stage was crucial" (Solution Engineer, Spendfix). In line with these challenges several interviewees request a more end-to-end journey responsibility. Summarizing, innovative projects seem to suffer the most from clear roles, responsibilities and sponsorship, offering the right organizational support for digitization also found in the theory [33].

\section{Discussion and future research}

This study contributes to the body of work on IT governance by extending it to radical and disruptive
IT-enabled innovations. Our findings show that existing governance frameworks that are applied to these innovations, that are often managed as agile projects or initiatives, have gaps or unclear and intransparent areas, leading to an unsupportive process for teams that rely on short and fast iterations in the development and deployment stage. Better alignment between the governance processes and the work of innovation teams should be encouraged to accelerate time to market [18].

For innovative projects, the traditional infrastructure landscape is perceived as limiting, further slowing down digital transformation initiatives. This is related to legacy technology with an old, obsolete system's architecture that is difficult to connect to novel technologies, and complications in the traceability of data, but also management controls and other ITG processes, mechanisms and structures. Although we found no direct support for the idea that controls are stricter for innovation projects, we did see a strong focus on risk avoidance, which is two-fold. First, we found that, while an innovative mindset is encouraged, also found in the theory [5], the organizational structure and decision making processes offer little room for the effectuation of these mindsets. The risk frameworks are black or white, offering one-size-fits-all. The case study results show the strong and urgent need for an intermediate "grey" solution for projects that are in an exploratory phase involving novel techniques, and room for that within the practical application of the ITG frameworks and guidelines. Related to that, we found that the number of gatekeepers is experienced as excessive and inefficient for these innovations.

Finally, we found solid evidence that business-IT alignment challenges have a strong correlation with the failure of innovation projects. We found that organizational culture and structure limited teams to accelerate, often caused by full backlogs or a lack of stakeholder participation.

Overall, this study shows which challenges occur when a large traditional organizations starts to embrace new innovations with one foot still firmly planted in old technologies, architectures and practices. Innovation often follows new paths, crossing business lines and involving multiple silos. This requires specific attention towards a set of ITG processes, structures and mechanisms that can offer a platform for innovation balancing short-term needs and long-term objectives. This study exposes the gap that exists between the theoretical IT governance frameworks and their application to address this. Our research thereby offers a valuable perspective for both high-level and mid-level managers to gain insights in 
the barriers for innovations and promoting, improving and applying ITG frameworks.

Obviously, our study is not without limitations. With seven cases, all embedded within a single organization in a specific sector, generalization claims need to be very modest. However, our findings show similarities with other studies indicating similar IT characteristics and experiences across industries, suggesting our results are at least partially generalizable. A second limitation of our study is that we solely looked at the internal barriers for innovation in the form of IT governance processes, structures and mechanisms. Hereby we automatically exclude external barriers possibly impacting the cases e.g. market and technological turbulence as well as competitor presence, this disqualifies insights on external dynamics influencing IT portfolio innovation. Although external variables are not part of the study, this research offers an initial step in investigating and understanding of the matter.

Important for the comprehensiveness of this review is that we assessed company structures, frameworks and literature as well as the conduction of qualitative interviews, this minimizes the possibility of missing important links. Future research should aim to the root causes of the barriers identified in this study. This can be done by conducting an in-depth study of the governance mechanisms and comprehension. Second, further generalizing these findings by expanding the scope of reference towards other organizations and sectors to compare results will contribute to the validity. Third, further research could be executed in a more detailed study on how new IT governance approaches should be shaped for innovative projects by formulating best practices.

\section{References}

[1] A. Bharadwaj, O. A. El Sawy, P. A. Pavlou, and N. Venkatraman, "Digital Business Strategy: Toward a Next Generation of Insights,” MIS Q., vol. 37, no. 2, pp. 471-482, 2013.

[2] A. Prasad, P. Green, and J. Heales, "On it governance structures and their effectiveness in collaborative organizationals structures," nternational J. Account. Inf. Syst., vol. 13, no. 3, pp. 199-220, 2012.

[3] H. Volberda, F. A. Van Den Bosch, and K. Heij, Reinventing Business Models: How Firms Cope with Disruption. Oxford University Press, 2018.

[4] E. Valentine and G. Stewart, "Enterprise Business Technology Governance: Three Competencies to Build Board Digital Leadership Capability," in 2015 48th Hawaii International Conference on System Sciences, 2015, pp. 4513-4522.
[5] V. Sambamurthy, S. Anandhi, and V. Grover, "Shaping Agility Through Digital Options: Reconceptualizing the Role of Information Technology in Contemporary Firms," MIS Q., vol. 27, pp. 237-263, 2003.

[6] J. Bradley, J. Loucks, j Macaulay, J. Macaulay, A. Noronha, and M. Wade, "Digital Vortex," 2015.

[7] I. Haffke, T. U. Darmstadt, B. Kalgovas, and A. Benlian, "The Transformative Role of Bimodal IT in an Era of Digital Business," in Proceedings of the 50th Hawaii International Conference on System Sciences, 2017, pp. $5460-5469$.

[8] S. De Haes and W. Van Grembergen, “An Exploratory Study into IT Governance Implementations and its Impact on Business/IT Alignment," Inf. Syst. Manag., vol. 26, pp. 123-137, 2009.

[9] ITGI, "Global Status Report on the Governance of Enterprise It (GEIt)-2011,” 2011.

[10] P. Weill, “Don't Just Lead, Govern: How topperforming firms govern IT," MIS Q. Exec., vol. 3, no. 1, pp. 1-17, 2004.

[11] C. M. Christensen, M. Raynor, and R. Mcdonald, "THE BIG IDEA What Is Disruptive Innovation?," HBR, pp. 1-11, 2015.

[12] V. Govindarajan, P. K. Kopalle, and E. Danneels, "The Effects of Mainstream and Emerging Customer Orientations on Radical and Disruptive Innovations," J. Prod. Innov. Manag., vol. 28, no. s1, pp. 121-132, Nov. 2011.

[13] J. Bowers and A. Khorakian, "Integrating risk management in the innovation project," EsmeraldInsight, pp. 25-40, 2014.

[14] J. A. Keizer, J.-P. Vos, and J. I. M. Halman, "Risks in new product development: devising a reference tool," R D Manag., vol. 35, pp. 297-309, Jun. 2005.

[15] L. Caluwe and S. De Haes, "Board Engagement in IT Governance: Opening Up the Black Box of IT Oversight Committees at Board Level," in Proceedings of the 52nd Hawaii International Conference on System Sciences, 2019, pp. 6189-6198.

[16] P. Zhang, K. Zhao, and R. L. Kumar, "Impact of IT Governance and IT Capability on Firm Performance," Inf. Syst. Manag., vol. 33, no. 4, pp. 357-373, 2016.

[17] E. N. Nfuka and L. Rusu, "Critical success factors framework for implementing effective IT governance in public sector organizations," J. Glob. Inf. Technol. Manag. , vol. 16, pp. 53-77, 2011.

[18] F. Schlosser and H.-T. Wagner, "IT Governance practices for improving strategic and operational BusinessIT alignment," in PACIS 2011 - 15th Pacific Asia Conference on Information Systems: Quality Research in Pacific, 2011, p. 167. 
[19] I. Smeekes, H. Borgman, and H. Heier, "A Wheelbarrow Full of Frogs: Understanding Portfolio Management for Agile Projects," in Proceedings of the 51stHawaii International Conference on System Sciences, 2018, pp. 5473-5482.

[20] V. Sambamurthy and R. W. Zmud, "Arrangements for Information Technology Governance: A Theory of Multiple Contingencies," Source MIS Q., vol. 23, no. 2, pp. 261-290, 1999.

[21] K. Sabine, "Adopting the cloud: how it affects firm strategy," J. Bus. Strategy, vol. 40, no. 4, pp. 28-35, Jan. 2019.

[22] P. Das, R. Verburg, A. Verbraeck, and L. Bonebakker, "Barriers to innovation within large financial services firms An in-depth study into disruptive and radical innovation projects at a bank,” Eur. J. Innov. Manag. Cit., 2017.

[23] A. Tiwana and B. Konsynski, "Complementarities Between Organizational IT Architecture and Governance Structure,” Inf. Syst. Res., pp. 1-17, 2009.

[24] M. Broadbent and P. Weill, "Management by Maxim: How Business and IT management can create IT infrastructures," Sloan Manage. Rev., vol. Spring, 1997.

[25] J. Hagel and M. Singer, "Unbundling the corporation," Harv. Bus. Rev., vol. 77, no. 2, pp. 1-8, 1999.

[26] P. Tallon and A. Pinsonneault, "Competing Perspectives on the Link Between Strategic Information Technology Alignment and Organizational Agility: Insights From a Mediation Model," MISQ, vol. 35, pp. 463-486, 2011.

[27] P. Aasi, L. Rusu, D. Leidner, E. Perjons, and M. Corrales Estrada, "How Does the Organizational Culture of Collaborative Networks Influence IT Governance Performance in a Large Organization?," in Proceedings of the 51stHawaii International Conference on System Sciences, 2018, pp. 4941-4951.

[28] P. Ribbers, R. Peterson, and M. Parker, "Designing Information Technology Governance Processes: Diagnosing Contemporary Practices and Competing Theories," in Proceedings of the 35th Hawaii International Conference on System Sciences, 2002, p. 241.

[29] J. W. Ross, "Creating a Strategic IT Architecture Competency: Learning in Stages Massachusetts Institute of Technology," MIT Sloan Sch. Manag. Work. Pap., vol. 2, pp. 1-15, 2003.

[30] P. Weill and R. Woodham, “Don't just lead, govern: Implementing Effective IT Governance," MIT Sloan, vol. 326, 2002.

[31] A. C. Boynton, G. C. Jacobs, and R. W. Zmud, "Managing information technology: just whose responsibility is it?," Sloan Manage. Rev., vol. 33, pp. 32$38,1992$.
[32] P. Weill and J. W. Ross, "IT Governance on one page," SSRN Electron. J., vol. 349, 2004.

[33] S. Héroux and A. Fortin, "The Influence of IT Governance, IT Competence and IT-Business Alignment on Innovation," Cah. Rech., vol. 04, pp. 1-36, 2016.

[34] S. De Haes and W. van Grembergen, "Analysing the Relationship between IT Governance and Business / IT Alignment Maturity," in Proceedings of the 41st Hawaii International Conference on System Sciences, 2014, no. May, pp. 1530-1605.

[35] L. Aversano, C. Grasso, and M. Tortorella, "A literature review of Business/IT Alignment Strategies," Procedia Technol., vol. 5, pp. 462-474, 2012.

[36] J. C. Henderson and N. Venkatraman, "Strategic alignment: Leveraging information technology for transforming organizations," Repr. FROM IBM Syst. J., vol. 32, no. 1, pp. 473-484, 1993.

[37] R. Yin, K, Case Study Research and Applications, 6th ed. 2018.

[38] P. C. Meijer, N. Verloop, and D. Beijaard, "MultiMethod Triangulation in a Qualitative Study on Teachers' Practical Knowledge: An Attempt to Increase Internal Validity," Qual. Quant., vol. 36, pp. 145-167, 2002.

[39] W. Van Grembergen, S. De Haes, and E. Guldentops, Structures, Processes and Relational Mechanisms for IT Governance 1 Chapter I Structures, Processes and Relational Mechanisms for IT Governance. 2004.

[40] K. M. Eisenhardt, "Building Theories from Case Study Research," Acad. Manag. Rev., vol. 14, no. 4, pp. 532-550, 1989.

[41] I. Bojanova and A. Samba, "Analysis of Cloud Computing Delivery Architecture Models," in International Conference on Advanced Information Networking and Applications, 2011, pp. 453-458. 